the Second World War. His chapter on the Budapest in which von Neumann grew up, for example - potentially a fascinating and lively study of a pre-First World War culture as intriguing as its Habsburg counterpart, Vienna leans far too heavily on statistics ("By 1910 Jews made up around $60 \%$ of Budapest's doctors and lawyers") and makes little attempt to breathe life into these facts or to use them to conjure up in the reader's imagination a world that, though now largely forgotten, produced, in addition to von Neumann, Theodore von Kármán, Michael Polayani, Eugene Wigner, Edward Teller and Leo Szilard.

In connection with this, one should also point out that the general standard of scholarship throughout the book is not very high. In places, Macrae makes heavy use of work that has already been published, and although in his notes he makes clear which particular books he is dependent on, he very rarely gives the exact source of his quotations or of his information. This is a pity, because where I am in a position to check his information, the number of mistakes he makes does little to inspire confidence in the rest. He has three or four pages on Bertrand Russell, for example, in which almost every paragraph contains an egregious error. Russell's grandfather, Lord John Russell, for instance - a radical Foxite Whig for whom anti-Toryism was practically a religion - is described by Macrae as "a right wing former British prime minister" and a "promising young conservative politician at the time of Waterloo".

There must, then, be doubts about how far we can trust Macrae for an assessment of von Neumann's work, especially in the field of politics. His prejudice in favour of a hawkish, rightwing opposition to communism is plain for all to see, as is his willingness to distort the views of his opponents. Nevertheless, in part because of Macrae's personal commitment, the sections of the book dealing with von Neumann's work on the 'Fat Man' bomb that was dropped on Nagasaki and his role in first developing the hydrogen bomb and then advising Eisenhower's government on the deployment of thermonuclear weapons are unfailingly fascinating. In dealing with the politics and personalities of committees, Macrae shows the confidence and the sure touch that was missing in his earlier accounts of mathematical logic.

What made Hodges's book on Turing such a stunning success was the author's ability to move around between three apparently unrelated subjects: the persecution of homosexuals in British society, the cracking of the 'Enigma' code and the development of computer models of the mind. A successful biogra- phy of von Neumann would need to show a similar, perhaps even greater, range of interests. In this deeply flawed work, Macrae has done little more than hint at what such a book would be like. $\square$

Ray Monk is in the Department of Philosophy, University of Southampton, Highfield, Southampton SO9 5NH, UK.

Of related interest is Prisoner's Dilemma: John von Neumann, Game Theory and the Puzzle of the Bomb by William Poundstone, now published in paperback by Oxford University Press (£7.99) and Ancior/Üoubiedáy (\$12.95): För a review by Martin Shubik, see Nature 356, 637 (1992)

\section{Have book, will travel}

\section{Karl Sigmund}

Reality Rules: Picturing the World in Mathematics. Volume 1: The Fundamentals. Volume 2: The Frontier. By John L. Casti. Wiley: 1992. Pp. 388/ 424. $\$ 80, £ 42.50$ (two-volume set).

STARTING with the Necker-cube-like ambiguity of its title and going right up to a discussion of alternative interpretations $f$ quantum reality in the final chapter, Reality Rules invites one continuously to shift one's position. This plea for mobility is characteristic of Iohn Casti's book. It is essentially a sightseer's guide to the fairyland of mathematical models, and aims at enticing one to book for a tour.

Casti Tours offers the most spectacular vistas of modern applied mathematics - including (of course) chaos theory, fractals, computational complexity, NPcompleteness, artificial life and cellular automata, as well as such topics as catastrophe theory and game theory that are no longer the current rage but still provide reliable, well-tested thrills. Even the more down-to-earth topics on the agenda, such as linear systems and control theory, are replete with 'souped-up' applications ranging from Searle's 'Chinese room' test for artificial intelligence to a party-goer's optimal drinking policy. With the exception of a chapter on connective structures, which seems somewhat at odds with the other chapters, the common thread running through the book is dynamical systems in one guise or another.

The book grew out of Alternative Realities, a widely acclaimed work published in 1989 that was awarded a best book prize by the American Association of Publishers. In the meantime the book has grown by 300 pages and split into two handsome volumes. The main changes include a substantial new chapter on computation and complexity, a wealth of exercises, problems and discussion questions, a solutions manual available on request and a wholesale updating of the text.

The book's style can best be seen by considering the author's antecedents. Casti started out as a systems scientist at the Rand Corporation, and wrote several mathematical textbooks before launching into science writing for the general public with his well-received books Pâradig̀ms Liost (Mórrow, 1989) and Searching for Certainty (Morrow, 1990) - reviewed in Nature 385, 293-4; 1992). Reality Rules occupies a niche somewhere between a textbook and a trade book. It is intended for readers with some training in undergraduate mathematics and a curiosity about the latest 'bestseller themes' in the scientific arena. Not incidentally, Casti nowadays works at the Santa Fe Institute, a hotbed of avant garde activities in dynamic systems modelling.

The two chapters bracketing the book are general discussions about the aims and limitations of mathematical modelling. Each of the eight chapters in between outlines enough material for at least a one-term graduate course. These surveys are to a large extent independent of one another (so that the same topics are sometimes approached from several perspectives), but they are not meant to be self-contained. On the contrary: in a sense, the climax of each chapter is reached with the six to ten superb pages of notes and references, which cover the relevant literature in an informal, agreeably chatty and extremely user-friendly way. I found them most helpful, both in fields I am familiar with and in those areas where I am a stranger. They offer reliable, thoroughly up-to-date advice for mathematical globe-trotting.

The text is designed to whet one's wanderlust. It is mostly a blend of simple yet instructive examples and heroic theorems. The general impact of these theorems is then analysed in a conversational style that leads up to a collection of stimulating discussion questions. Casti's formula is thus to invite the reader to take some easy steps first and then offer a breath-taking view of the heights. The notion of an algorithm, for instance, is explained by means of a detailed recipe for Caesar's salad, but just a few pages later one is up to one's ears in uncomputable numbers. In much the same vein, the exercises are a mixed bag some straightforward classroom drill problems together with many thoroughly hard nuts that on occasion summarize entire research articles, sending one scurrying to the solutions manual. These 
abrupt shifts. in gear can be upsetting, especially as they are hidden by Casti's easy style, which can cause one to exceed the speed limit. The book deserves to be taken at leisure. Breezing too rapidly through Reality Rules, one might get the impression that it really reels.

Like most travel guides, the book does not recoil from hype; but it is used in a relaxed way, secure in the confidence that if readers don't buy one cruise, they'll book another. This nonchalance reflects the current trend away from theories toward models. A theory can have supporters and opponents, each committed to the hilt; but a model cannot cause fanaticism - you're free to take it or leave it in the tolerant eclecticism of the Roman Pantheon. Casti is no button-holing zealot out to convince. In fact, his lines are studded (artfully, I suspect) with casual asides meant to provoke even the most docile of readers into occasional mutterings, containing such off-handed remarks as that Western science arose because the 'competition' was unable to come up with a satisfactory explanation of the Black Death, and claiming that some innocuous incidence matrix yields 'insight' into a Shakespearean sonnet. But these are minor eddies in a broad stream; the tale runs smoothly on, and carries such a wealth of information that one doesn't feel like quibbling over matters of opinion with such an urbane cicerone. As a racy synopsis covering a huge area, Reality Rules will best be enjoyed by scientists who have retained not just a working knowledge of college mathematics, but also a youthful taste for the excitement of heady intellectual adventure.

Karl Sigmund is in the Institute for Mathematics, University of Vienna, Strudlhofgasse 4, A-1090 Vienna, Austria.

\section{Symmetry for the armchair}

\section{Simon L. Altmann}

Symmetry in Chaos: A Search for Pattern In Mathematics, Art and Nature. By Michael Field and Martin Golubitsky. Oxford University Press: 1992. Pp. 218. $£ 19.95, \$ 35$.

Reflections on Symmetry in Chemistry... and Elsewhere. By Edgar Heilbronner and Jack D. Dunitz. VCH: 1993. Pp. 154. DM58, £22.

The Dynamics of Ambiguity. By Giuseppe Caglioti. Springer: 1992. Pp. 170. DM98, $£ 40$.

EVER since Hermann Weyl published his famous Symmetry in 1952 many have been called to write on the subject; few, however, are those who can move, like Weyl, with equal authority from Hans Castorp to the problem of inversion in Raphael's cartoons. In Symmetry in Chaos, Michael Field and Martin Golubitsky, quite wisely, have given themselves a different remit and have succeeded in producing a book that is in itself a work of art: not a minor achievement for a book on mathematics. They have in fact invented a wonderful scheme to produce two-dimensional coloured patterns by computer.

If you allow your cursor to perform a random walk, pixel by pixel, on a computer screen and if you have a colour scale in which the pixel colour is determined by the number of visits that it has received, you will of course get, after sufficient iteration, a uniformly coloured rectangle. Field and Golubitsky, instead, superimpose on this process an attractor, in the sense of chaos theory. This is an iteration scheme that will guide the ac670

joined the ranks of the great inventors of two-dimensional patterns, from the craftsmen of the Alhambra to the modern ceramic, textile and wallpaper designers.

A general book on symmetry that does not quote or reproduce $M$. C. Escher is a rare one these days and Field and Golubitsky's is no exception to the rule. But in Reflections on Symmetry in Chemistry... and Elsewhere, Edgar Heilbronner and Jack D. Dunitz go further, because they are the first people I know of to point out that patterns in which the background is a translated mirror image of the foreground were in fact invented by Kolo Moser decades before Escher. Anyone fortunate enough to gain access to the recently refurbished (but alas still erratically open) Museum für Angewandte Kunst in Vienna can see a cabinet by Moser with a marquetry frieze where the positive and negative layers are identical after reflection (in practice, a 180-degree rotation about an axis on the layer) and translation. It is possible that the challenge to achieve this in marquetry drove Moser's invention, but he also used the idea in textile design.

This detail in Heilbronner and Dunitz's book is typical of the meticulous care with which it has been written. Without any mathematics, the more important ideas arising from group theory are given and beautifully

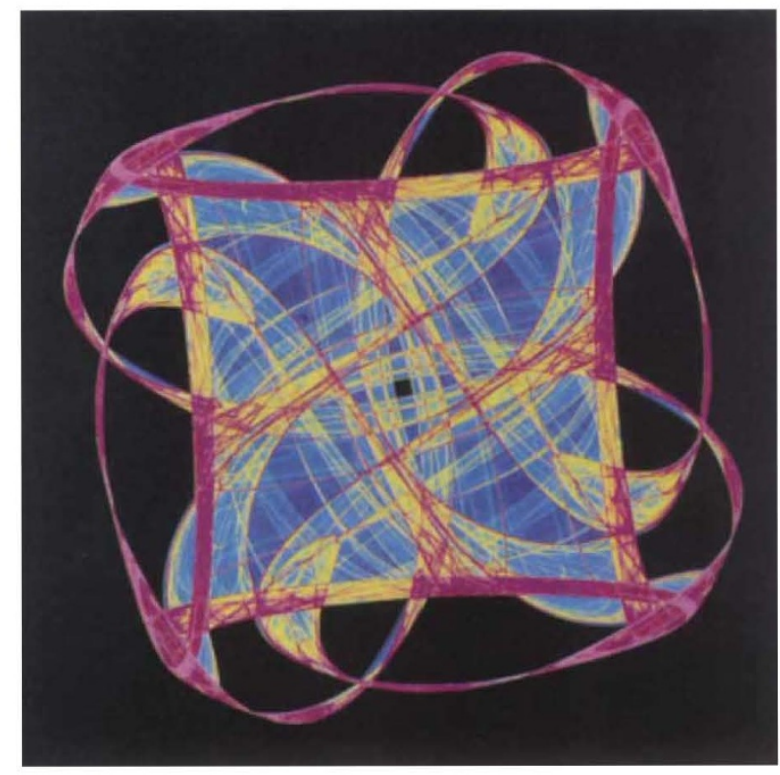

Swirling Streamers taken from Symmetry In Chaos. illustrated. To achieve such a degree of informed simplicity is indeed most difficult and the authors even succeed in explaining sufficiently the concept of irreducible representation so as to be able to discuss Woodward and Hoffmann's rules. But there is a great deal more in this excellent work, from very illuminating symmetry games to historical discussions on the use of symmetry principles. This is a book that one can warmly recommend to intelligent sixth-formers and undergraduates alike.

Such an audience, however, cannot easily be imagined for The Dynamics of Ambiguity by

tion of the mathematics to make their method understandable, as well as the ideas behind it, and full programs in BASIC are given in the appendices. As the authors themselves say, the question whether these pictures, and the underlying mathematics, will be of lasting scientific interest "is one that has yet to be answered". These two mathematicians, on the other hand, have now
Giuseppe Caglioti, now translated from the Italian by A. O. Bucci. But none of its readers will fail to be struck by the width of the author's interest in broken symmetries, from quantum mechanics, music and art analysis à la Arnheim, to Virgil's poetry.

Simon L. Altmann is at Brasenose College, Oxford OX1 4A, UK.

NATURE · VOL $362 \cdot 15$ APRIL 1993 